УДК 332.12

ББК 65.04

ФОРМИРОВАНИЕ РЕГИОНАЛЬНЫХ АГРОПРОМЫШЛЕННЫХ КЛАСТЕРОВ: ПРИМЕР ГОМЕЛЬСКОЙ ОБЛАСТИ

\author{
Н. П. ДРАГУН \\ dragunnp@,gmail.com \\ кандидат экономических наук, доцент, заведующий кафедрой «Экономика» \\ Гомельский государственный технический университет им. П.О. Сухого \\ Гомель, Республика Беларусь \\ Ю. А. ВОЛКОВА \\ volkova.gstu@gmail.com \\ старший преподаватель кафедры «Экономика» \\ Гомельский государственный технический университет им. П.О. Сухого \\ Гомель, Республика Беларусь \\ И. В. ИВАНОВСКАЯ \\ ivanovskayaiv@gmail.com \\ кандидат экономических наук, доцент, \\ заведующий кафедрой «Экономика и управление» \\ Белорусско-Российский университет \\ Могилев, Республика Беларусь
}

На основе проведенного в 2016 г. мониторинга кластерного развития экономики Гомельской области впервые представлен перечень, состав и географическая локализаиия базовых организаций и участников потенциальных агропромышленных кластеров региона. Сформулированы практические рекомендации, направленные на формирование и эффективное функиионирование агрокластеров области.

Ключевые слова: агропромышленный кластер, базовая организация, вертикальноинтегрированный кластер, интеграция, район, фактор.

\title{
FORMATION OF REGIONAL AGRICULTURAL CLUSTERS: EXAMPLE OF THE GOMEL REGION
}

\author{
M. P. DRAHUN \\ dragunnp@gmail.com \\ $\mathrm{PhD}$ in Economics, Associate Professor, Head of the Department "Economics" \\ P. Sukhoi Gomel State Technical University \\ Gomel, Republic of Belarus \\ Yu. A. VOLKAVA \\ volkova.gstu@gmail.com \\ Senior Lecturer of the Department "Economics" \\ P. Sukhoi Gomel State Technical University \\ Gomel, Republic of Belarus \\ I. V. IVANOUSKAYA \\ ivanovskayaiv@gmail.com \\ $\mathrm{PhD}$ in Economics, Associate Professor, \\ Head of the Department "Economics and Management" \\ Belarusian-Russian University \\ Mogilev, Republic of Belarus
}


Based on the information of monitoring activities of the cluster development of the economy of the Gomel region conducted in 2016, the list, composition and geographic location of the basic organizations and participants of potential agro-industrial clusters of the region is presented for the first time. Practical guidance aimed at the formation and efficient operation of agro-clusters of the region are formulated.

Keywords: agro-industrial cluster, reference organization, vertically integrated cluster, integration, area, factor.

\section{ВВЕДЕНИЕ}

В государственных программных документах интеграция агропромышленных организаций рассматривается в качестве одного из наиболее перспективных механизмов повышения эффективности их деятельности [1]. Интеграция позволяет путем роста эффективности взаимодействия изменять структуру рынка для увеличения рыночной власти организаций на нем, снижать транзакционные издержки и риски их взаимодействия, производственные и сбытовые издержки организаций как на основе роста уровня концентрации спроса (используя закон опыта) и предложения (используя эффекты масштаба и разнообразия), так и обеспечения необходимого объема инвестиций в специфические активы $[2 ; 3 ; 4]$.

До настоящего времени в агропромышленном комплексе Беларуси в силу целого ряда институциональных причин - большая доля государственной собственности в экономике, высокая централизация управления, особенности организации отечественного АПК (например, высокая концентрация производства, изначально низкий уровень вертикальной интеграции сельхозорганизаций и перерабатывающих предприятий, а также взаимодействие организаций АПК преимущественно на основе кооперации) и др. - интеграция осуществлялась в «жесткой» иерархической форме преимущественно путем создания вертикально интегрированных структур холдингового типа на основе технологической взаимосвязи организаций $[1 ; 5]$. С одной стороны, это позволило повысить эффективность использования ими производственных ресурсов и мощностей, расширить сырьевую базу переработки, ослабить проблему дефицита оборотных средств, особенно когда речь идет об организациях, осуществляющих начальные этапы создания добавленной стоимости (сельхозорганизациях). А поскольку такие организации, как правило, локализованы на сельских территориях, постольку создание интегрированных структур стало эффективным инструментом реализации региональной экономической и социальной политики. В то же время холдинговая интеграция в гораздо меньшей степени положительно повлияла на финансовое состояние организаций, рост их инвестиционной (а, следовательно, и инновационной) активности и рыночной власти вследствие Х-неэффективности. Ее источниками послужили несовершенное законодательство, регулирующее деятельность холдингов, мягкие бюджетные ограничения, высокая значимость социальных целей функционирования, ограничение конкуренции, отсутствие опыта управления крупными объединениями организаций холдингового типа и использование устаревших управленческих технологий. Все это не позволило получить значительные синергетические эффекты взаимодействия организаций в рамках агропромышленных холдингов.

По нашему мнению, одним из путей решения названных проблем является развитие в отечественном АПК «мягких» форм интеграции в виде кластеров. Так, Стратегия устойчивого развития Гомельской области на период до 2025 г. в качестве региональных точек роста предусматривает создание и функционирование агрокластеров по производству мясной и молочной продукции [6]. Кластеры на основе географической локализации организаций, их кооперационного взаимодействия и механизма соконкуренции позволяют 
при благоприятных условиях не только достичь тех же целей, что и «жесткая» иерархическая интеграция, но и существенно ослабить проблему Х-неэффективности, повысить инновационную и инвестиционную активность участников $[7 ; 8 ; 9]$.

Несмотря на имеющееся большое количество исследований, посвященных проблемам кластерного развития, многие прикладные задачи формирования и обеспечения эффективного функционирования кластерных структур остаются нерешенными. Особенно это касается задач формирования кластерных структур на конкретных территориях, в том числе территории Гомельской области Беларуси. Указанные обстоятельства обусловили актуальность настоящего исследования, его научную и практическую значимость.

Цель исследования - выявить потенциальные агрокластеры на территории Гомельской области, определить состав их участников и их географическую локализацию.

Работа выполнялась в рамках реализации Проекта международной технической помощи ЕС «Поддержка регионального и местного развития в Республике Беларусь» при поддержке Гомельского областного исполнительного комитета на основе Методических рекомендаций по организации и осуществлению мониторинга кластерного развития экономики [10]. В качестве источников информации для мониторинга использовались данные Национального статистического комитета Республики Беларусь, Гомельского областного исполнительного комитета, результаты проведенного в 2016 г. анкетирования предприятий и организаций Гомельской области. Всего проанкетированы 91 организация, $19 \%$ из которых расположены в г. Гомеле, 11 \% в Калинковичском, 10 \% в Мозырском, по 8 \% в Октябрьском и Ельском, 7 \% в Ветковском, по 5 \% в Речицком и Гомельском, по 4 \% в Брагинском, Буда-Кошелевском и Рогачевском, 3 \% в Светлогорском, по 2\% в Житковичском, Жлобинском, Лоевском, Хойникском, Чечерском районах.

\section{РЕЗУЛЬТАТЫ И ИХ ОБСУЖДЕНИЕ}

В результате проведенного исследования нами было выявлено 7 потенциальных специализированных агропромышленных вертикально-интегрированных кластеров по производству мяса птицы и яиц (1 кластер), продуктов переработки мяса (1), продуктов переработки молока (3), хлебопродуктов (1), продуктов из масличных культур (1), а также 6 неспециализированных вертикально-интегрированных кластера по производству продуктов переработки мяса и молока, хлебопродуктов.

Потенцииальный специализированный вертикально-интегрированный агрокластер по производству мяса птицьы и яии включает 8 организаций, 50 \% которых географически локализованы в г. Гомеле и Гомельском районе, 25 \% в Мозырском, по 12,5 \% в Буда-Кошелевском и Светлогорском районах.

Базовыми организациями кластера выступают ОАО «Птицефабрика «Рассвет», ОАО «Гомельская птицефабрика» (Гомельский р-н), РДСУП «Белоруснефть-Особино» (Буда-Кошелевский р-н), КСУП «Совхоз-комбинат «Заря» (Мозырский р-н). Также в состав кластера входят ОАО «Светлогорский целлюлозно-картонный комбинат» (Светлогорский р-н), ЧУП «Гомельский завод торгового оборудования», ООО «Навальница», ОАО «Гомельоблагросервис» (г. Гомель), потенциальным партнером является ОАО «Мозырьтехсервис».

Потенциальный специиализированный вертикально-интегрированный агрокластер по производству продуктов переработки мяса включает 27 организаций, 18,5 \% которых географически локализованы в Ельском, 14,8 \% в Калинковичском, по 11,1 \% в Ветковском и Рогаческом, по 7,4 \% в Брагинском, Мозырском и Чечерском, по 3,7 \% в Буда-Кошелевском, Жлобинском, Лоевском, Речицком и Хойникском районах, а также г. Гомеле. 
Базовыми организациями кластера выступают ОАО «АФПК «Жлобинский мясокомбинат», ОАО «Калинковичский мясокомбинат», ОАО «Гомельский мясокомбинат». Участниками кластера являются: ОАО «Маложинский», ОАО «Совхоз «Комаринский» (Брагинский р-н), СУП «Андреевка» (Буда-Кошелевский р-н), ОАО «Столбунский», УСП «Искра-Ветка», УСП «Радуга-Агро» (Ветковский р-н), КСУП «Совхоз «Коммунист», КСУП «Ельск», КСУП «Добринь», КСУП «Ельское полесье», КСУП «Скороднянский» (Ельский р-н), ТД ОАО «Калинковичский мясокомбинат», ОАО «Прудокское», ПУП «Калинковичское зверохозяйство Белкоопсоюза» (Калинковичский р-н), КСУП «Малиновка-Агро» (Лоевский р-н), РСУП Э/Б «Криничная», КСУП «Совхоз-комбинат «Заря» (Мозырский р-н), СУП «Речицкий-Агро» (Речицкий р-н), ОАО «Альтаир», ОАО Селекционно-гибридный центр «Заречье», ОАО «Тихиничи» (Рогачевский р-н), ОАО «Отор», ОАО «Звезда» (Чечерский р-н), КСУП «Оревичи» (Хойникский р-н).

Потенциильные специализированные вертикально-интегрированные агрокластеры по производству продуктов переработки молока включают 57 организаций, 12,3 \% которых географически локализованы в Октябрьском, 10,6 \% в г. Гомеле и Гомельском, 10,5 \% в Калинковичском, по 8,8\% в Мозырском и Ельском, 7,0 \% в Рогачевском, по 5,3\% в Брагинском, Буда-Кошелевском, Ветковском, Речицком, Светлогорском, по 3,5 \% в Житковичском, Лоевском, Хойникском, Чечерском, 1,8 \% в Жлобинском районах:

- базовыми организациями первого кластера выступают ОАО «Туровщина», ОАО «Туровский молочный комбинат» (Житковичский р-н), ОАО «Рогачевский молочноконсервный комбинат» (Рогачевский р-н). Участниками кластера являются: ОАО «Столбунский» (Ветковский р-н), ИП УП «Фрешпак Салюшенс», ОАО «Гомельоблавтотранс», ОАО «Гомельагротранс» (г. Гомель), ПСК «50 лет Октября» (Речицкий р-н), ОАО «Тихиничи», ОАО «Альтаир», ОАО «Селекционно-гибридный центр «Заречье» (Рогачевский р-н), ОАО «Отор», ОАО «Звезда» (Чечерский р-н);

- базовыми организациями второго кластера выступают ПУП «Калинковичский молочный комбинат» и ОАО «Октябрьский завод сухого обезжиренного молока». Участниками кластера являются: ОАО «Гомельхимторг» (г. Гомель), ОАО «Прудокское», ЧПТУП «Кубк-пак», СПК «Дружба Автюки», ОАО «Родина» (Калинковичский р-н), ОАО «Мозырьсоль», ООО «Торговый дом Рогачевъ», КПУП «Мозырские молочные продукты» (Мозырский р-н), ОАО «Некрашинский», ОАО «Октябрьский-агро», ОАО «Моисеевка», ОАО «Поречье-Оресса», ОАО «Краснослободское», Унитарное предприятие по агрохимическому обслуживанию «Октябрьагрохимия» (Октябрьский р-н), РУП «Дуброва-Агро», КСУП «Вежны» (Светлогорский р-н);

- базовыми организациями третьего кластера выступают ОАО «Милкавита» (г. Гомель), СООО «Белсыр» (Калинковичский р-н), КПУП «Мозырские молочные продукты» (Мозырский р-н). Участниками кластера являются: ОАО «Совхоз «Комаринский», ОАО «Маложинский», ОАО «Чемерисский» (Брагинский р-н), Филиал ОАО «Гомельский завод сельскохозяйственного машиностроения» сельскохозяйственный комплекс «Юбилейный», СУП «Андреевка», ОАО «СП Амипак» (Буда-Кошелевский р-н), УСП «Искра-Ветка», УСП «Радуга-Агро» (Ветковский р-н), ОАО «Агрокомбинат «Южный» (Гомельский р-н), КСУП «Добринь», КСУП «Скороднянский», КСУП «Совхоз «Коммунист», КСУП «Ельск», КСУП «Ельское полесье» (Ельский р-н), ПУП «Калинковичский молочный комбинат» (Калинковичский р-н), КСУП «Малиновка-Агро», КСУП «Урожайный» (Лоевский р-н), ООО «Торговый дом «Рогачевъ», КСУП «Совхоз-комбинат «Заря», ОАО «Мозырьсоль» (Мозырский р-н), СУП «Речицкий-Агро», Филиал «Советская Белоруссия» ОАО «Речицкий КХП» (Речицкий р-н), ОАО «Светлогорский ЦКК» (Светлогорский р-н), КСУП «Оревичи» (Хойникский р-н). 
Потенциильный специализированный вертикально-интегрированный агрокластер по производству хлебопродуктов включает 17 организаций, 29,4 \% которых географически локализованы в Ельском, по 17,6 \% в г. Гомеле и Речицком, по 11,8 \% в Брагинском и Калинковичском, по 5,9 \% в Лоевском и Хойникском районах.

Базовыми организациями кластера выступают ОАО «Калинковичихлебопродукт» (Калинковичский р-н), ОАО «Речицкий комбинат хлебопродуктов» (Речицкий $\mathrm{p}-\mathrm{H}), \mathrm{OAO}$ «Гомельхлебопродукт» (г. Гомель). Участниками кластера являются: ОАО «Маложинский», ОАО «Совхоз «Комаринский» (Брагинский р-н), ОАО «Гомельский белково-жировой завод», ОАО «Гомельский жировой комбинат» (г. Гомель), КСУП «Добринь», КСУП «Скороднянский», КСУП «Совхоз «Коммунист», КСУП «Ельск», КСУП «Ельское полесье» (Ельский р-н), ОАО «Прудокское» (Калинковичский р-н), КСУП «Урожайный» (Лоевский р-н), СУП «Речицкий-Агро», КПТУП «Речицаагрохимсервис» (Речицкий р-н), КСУП «Оревичи» (Хойникский р-н).

Потенцииальный специализированный вертикально-интегрированный агрокластер по производству продуктов из масличных культур включает 3 организации. База кластера - ОАО «Гомельский жировой комбинат», организации-участники: ОАО «Маложинский» (Брагинский р-н), ОАО «Прудокское» (Калинковичский р-н).

Также выявлено 6 потенциальных вертикально-интегрированных неспециализированных агрокластеров по производству продуктов переработки мяса и молока, хлебопродуктов, включающие 42 организации, 16,7 \% которых географически локализованы в г. Гомеле и Ельском, 14,3\% в Ветковском, по 9,5\% в Брагинском и Гомельском, по 7,1 \% в Калинковичском и Мозырском, по 4,8 \% в Жлобинском, Лоевском и Речицком, по 2,4 \% в Буда-Кошелевском и Рогачевском районах.

\section{ВЫВОДЫ}

По результатам проведенного исследования факторов кластерного развития Гомельской области нами разработаны следующие практические рекомендации органам государственного управления, направленные на активизацию формирования агрокластеров:

- учитывая специфику экономики Гомельской области, создание кластеров в регионе предпочтительно осуществлять прежде всего в АПК, так как возможности для создания агрокластеров есть во всех административных районах области;

- развитие кластерных структур должно происходить преимущественно в виде вертикально-интегрированных специализированных кластеров, включающих помимо группы одноотраслевых конкурентов организации, являющиеся потребителями, поставщиками и др. Наиболее предпочтительным способом создания новых кластеров является их формирование «снизу» путем включения в кластеры вновь созданных организаций на базе единой производственной инфраструктуры. Создание кластеров на основе уже функционирующих организаций менее предпочтительно, поскольку большинство из них уже входят в другие интеграционные структуры;

- поскольку большинство перспективных для включения в кластеры организаций области уже входят в другие интеграционные структуры «жесткого» иерархического типа, которые по своим функциям конкурируют с кластерами, необходимо проанализировать эффективность этих «жестких» форм интеграции в АПК и при необходимости (то есть их меньшей эффективности) отказаться от них в пользу кластерных структур;

- должна быть пересмотрена роль вышестоящих управляющих органов и органов государственной власти как координаторов взаимодействия организаций в АПК, поскольку, чем выше координирующая роль данных органов, тем меньше стимулов у подчиненных организаций к созданию кластеров для взаимной координации деятельности; 
- в силу сложившейся в экономике области ситуации, роль органов государственной власти в активизации кластерного развития области чрезвычайно велика. Это подтверждают итоги создания интеграционных структур в агропромышленном комплексе региона, которые получены в рамках государственных программ развития АПК. В результате, сейчас практически в каждом административном районе возможно создание агрокластеров. Поэтому чрезвычайно важно выработать и реализовать эффективную государственную кластерную политику, которая, в том числе, может опираться на результаты настоящего исследования;

- значительным препятствием для создания кластеров является отсутствие у большинства организаций области четкого представления о сущности кластеров, их функциях и преимуществах перед другими интеграционными структурами. Нет также четкого понимания того, какие проекты могут быть реализованы путем создания кластеров. Поэтому широкое информирование руководства организаций АПК области по проблемам кластерного развития является необходимым условием для его активизации.

\section{СПИСОК ИСПОЛЬЗОВАННЫХ ИСТОЧНИКОВ}

1. Государственная программа развития аграрного бизнеса в Республике Беларусь на 2016-2020 годы // Министерство сельского хозяйства и продовольствия Республики Беларусь [Электронный ресурс]. - 2016. - Режим доступа: https://www. mshp.gov.by/prog/programma_agrobiznes.docx. - Дата доступа: 20.07.2017.

2. Бычков, Н. А. Аграрное кооперирование (теория, методология, практика) / Н. А. Бычков ; Акад. аграр. наук Респ. Беларусь, Белорус. науч.-исслед. ин-т аграр. экономики. - Минск, 2000. -252 с.

3. Гусаков, В. Г. Научные основы создания продуктовых компаний / В. Г. Гусаков, М. И. Запольский ; Нац. акад. наук Беларуси, Ин-т систем. исслед. в АПК НАН Беларуси. Минск : Беларус. навука, 2012. - 195 с.

4. Кусакина, О. Н. Социально-экономическая эффективность функционирования интегрированных структур в АПК: содержание и оценка / О. Н. Кусакина, Е. В. Скиперская // Управление экономическими системами: электронный научный журнал. - 2012. № 44. - С. 19-34.

5. Методические рекомендации по совершенствованию системы управления и экономических взаимоотношений участников интегрированных формирований регионального АПК / М. И. Запольский, Т. И. Ленская, М. С. Назарова, Е. В. Гусаков, М. В. Молохович, С. А. Чаусов. - Минск: РНУП «Институт системных исследований в АПК НАН Беларуси», 2014. - 60 с.

6. Стратегия устойчивого развития Гомельской области на 2016-2025 годы // Поддержка регионального и местного развития в Беларуси [Электронный ресурс]. - 2016. - Peжим доступа: http://regdev.by/ru/download/file/fid/144. - Дата доступа: 20.07.2016.

7. Гусаков, Е. В. Концепция создания и функционирования кластерных структур в аграрном комплексе / Е. В. Гусаков // Известия Национальной академии наук Беларуси. Серия аграрных наук. - 2016. - № 3. - С. 14-18.

8. Пилипук, А. В. Продуктовые кластеры в АПК Беларуси: актуальность и предложения по их формированию / А. В. Пилипук // Проблемы экономики : сб. науч. тр. / Белорус. гос. с.-х. акад., Ин-т систем. исслед. в АПК НАН Беларуси; редкол.: А. М. Каган [и др.]. - Минск, 2009. - Вып. 2 (9). - С. 222-235.

9. Субоч, Ф. И. Устойчивое динамическое развитие национальных и межнациональных продуктовых структур в инновационно-кластерной системе ЕЭП и ЕврАзЭС / 
Ф. И. Субоч // Экономические вопросы развития сельского хозяйства Беларуси : межведомств. темат. сб. / Ин-т систем. исслед. в АПК НАН Беларуси ; редкол.: В. Г. Гусаков [и др.]. - Минск, 2013. - Вып. 41. - С. 233-251.

10. Методические рекомендации по организации и осуществлению мониторинга кластерного развития экономики // NAVINY [Электронный ресурс]. - 2014. - Режим доступа: http://naviny.org/2014/12/01/by653.htm. - Дата доступа: 01.02.2016.

\section{REFERENCES}

1. Gosudarstvennaya programma razvitiya agrarnogo biznesa v Respublike Belarus' na 2016-2020 gody // Ministerstvo sel'skogo hozyajstva i prodovol'stviya Respubliki Belarus' [Ehlektronnyj resurs]. - 2016. - Rezhim dostupa: https:/www.mshp.gov. by/prog/programma_agrobiznes.docx. - Data dostupa: 20.07.2017.

2. Bychkov, N. A. Agrarnoe kooperirovanie (teoriya, metodologiya, praktika) / N. A. Bychkov ; Akad. agrar. nauk Resp. Belarus', Belorus. nauch.-issled. in-t agrar. ehkonomiki. - Minsk, 2000. - 252 s.

3. Gusakov, V. G. Nauchnye osnovy sozdaniya produktovyh kompanij / V. G. Gusakov, M. I. Zapol'skij ; Nac. akad. nauk Belarusi, In-t sistem. issled. v APK NAN Belarusi. Minsk : Belarus. navuka, 2012. - 195 s.

4. Kusakina, O. N. Social'no-ehkonomicheskaya ehffektivnost' funkcionirovaniya integrirovannyh struktur v APK: soderzhanie i ocenka / O. N. Kusakina, E. V. Skiperskaya // Upravlenie ehkonomicheskimi sistemami: ehlektronnyj nauchnyj zhurnal. - 2012. - № 44. - S. 19-34.

5. Metodicheskie rekomendacii po sovershenstvovaniyu sistemy upravleniya i ehkonomicheskih vzaimootnoshenij uchastnikov integrirovannyh formirovanij regional'nogo APK / M. I. Zapol'skij, T. I. Lenskaya, M. S. Nazarova, E. V. Gusakov, M. V. Molohovich, S. A. Chausov. - Minsk: RNUP «Institut sistemnyh issledovanij v APK NAN Belarusi», 2014. - $60 \mathrm{~s}$.

6. Strategiya ustojchivogo razvitiya Gomel'skoj oblasti na 2016-2025 gody // Podderzhka regional'nogo i mestnogo razvitiya v Belarusi [EHlektronnyj resurs]. - 2016. - Rezhim dostupa: http://regdev.by/ru/download/file/fid/144. - Data dostupa: 20.07.2016.

7. Gusakov, E. V. Koncepciya sozdaniya i funkcionirovaniya klasternyh struktur v agrarnom komplekse / E. V. Gusakov // Izvestiya Nacional'noj akademii nauk Belarusi. Seriya agrarnyh nauk. - 2016. - № 3. - S. 14-18.

8. Pilipuk, A. V. Produktovye klastery v APK Belarusi: aktual'nost' i predlozheniya po ih formirovaniyu / A. V. Pilipuk // Problemy ehkonomiki : sb. nauch. tr. / Belorus. gos. s.-h. akad., In-t sistem. issled. v APK NAN Belarusi; redkol.: A. M. Kagan [i dr.]. - Minsk, 2009. Vyp. 2 (9). - S. 222-235.

9. Suboch, F. I. Ustojchivoe dinamicheskoe razvitie nacional'nyh i mezhnacio-nal'nyh produktovyh struktur v innovacionno-klasternoj sisteme EEHP i EvrAzEHS / F. I. Suboch // EHkonomicheskie voprosy razvitiya sel'skogo hozyajstva Belarusi : mezh-vedomstv. temat. sb. I In-t sistem. issled. v APK NAN Belarusi ; redkol.: V. G. Gusa-kov [i dr.]. - Minsk, 2013. Vyp. 41. - S. 233-251.

10. Metodicheskie rekomendacii po organizacii i osushchestvleniyu monitoringa klasternogo razvitiya ehkonomiki // NAVINY [Ehlektronnyj resurs]. - 2014. - Rezhim dostupa: http://naviny.org/2014/12/01/by653.htm. - Data dostupa: 01.02.2016.

Статья поступила в редакцию 2 мая 2018 года. 